\title{
The Plagiarism Advisory Service
}

\author{
Fiona Duggan
}

\section{Author}

Fiona Duggan, the Manager for the JISC Plagiarism Advisory Service, is a former student of Northumbria University at both undergraduate and postgraduate levels.

\section{f.duggan@,northumbria.ac.uk}

\begin{abstract}
The issue of plagiarism in education has existed for many years, however, advances in technology resulting in easy access to a multitude of information sources has reduced the effort required to incorporate the work of others into an essay or report. A Plagiarism Advisory Service has been established to provide advice and guidance on all aspects of plagiarism prevention and detection. This article presents the background to the Advisory Service and the associated electronic Plagiarism Detection Service. The nature and operation of the detection software is such that it should always be viewed as an additional element of any plagiarism prevention strategy. Future plans for the Advisory Service include the development of tools aimed at improving students referencing and citation practice and encouraging academics to audit their own assessment practice.
\end{abstract}

\section{Introduction}

Plagiarism, the presentation of the work of another as your own original work, is not a new phenomenon. Technological advances, such as the internet and email, have however substantially increased the sources available for plagiarising, and significantly reduced the time and effort required to incorporate these sources into an essay or report. In addition, ready access to internet and email technology coupled with increased confidence in e-commerce has also led to a burgeoning industry that provides student essays at the click of a mouse and input of a credit card number. Although these 'essaybanks' or 'paper mills' are in the main US based, and serve a predominantly US focused clientele, there are now a number of sites aimed at students in the UK. It must, therefore, be assumed that the number and coverage of these sites is likely to increase in the future. Concerns about these trends and the potential they represent for a related increase in the occurrence of plagiarism led to the establishment of the Plagiarism Advisory Service in September 2002, providing advice and guidance on all aspects of plagiarism prevention and detection to institutions, academics and students. The service, which is fully funded by the Joint Information Systems Committee, JISC, is based in the Information Management Research Institute (IMRI) at Northumbria University. 


\section{Background}

The decision to fund an advisory service was founded in a series of pilot studies, conducted on behalf of the JISC in 2001, which considered the nature and efficacy of electronic plagiarism detection software programmes (Chester 2001, Bull et al., [n.d.], Culwin, McLeod \& Lancaster 2001) and the role of good practice in relation to plagiarism prevention (Carroll \& Appleton, 2001). The studies by Bull et al., (n.d.) and Culwin, McLeod and Lancaster (2001) considered the technical issues relating to freetext plagiarism detection software and source code plagiarism detection software respectively. The free-text study (Bull et al., n.d.) included a survey of academics to "determine the extent and nature of plagiarism" in addition to the technical evaluation of the software. The survey responses indicated that $50 \%$ of the 293 respondents to the questionnaire felt that "there has been an increase in plagiarism in recent years," and $42 \%$ of the respondents also felt that "plagiarism was harder to detect if it has been required from the Internet rather than from traditional resources" (Bull et al. n.d.). Electronic detection software is viewed by many in education as the solution to these problems. Chester's (2001) study, therefore, "set out to review the social and organisational impact of electronic plagiarism detection software." Detection software was trialled at five institutions, where initially twenty-five departments were involved in the project. The software programme selected for the project, turnitin, was one of the five detection programmes reviewed in Bull et al's study and was ultimately awarded the contract for the JISC Detection Service (see below). In general participants found the software easy to use, although some difficulties were experienced in relation to the time taken to produce the reports, in this case twenty-four hours, and in the response to queries due to the time delays inherent in dealing with a supplier based in California.

The pilot sites reported that students involved in the project were initially cautious about the software, but in general were willing to agree to the submission of work. Some concerns were, however, expressed about how the reports produced by the software would be used (Chester, 2001). In particular, students were concerned that inadvertent plagiarism would result in censure, and a survey of the students in one of the pilot departments highlighted their desire for "more time to be spent explaining the nature of plagiarism" (Chester, 2001).

Feedback from workshops held at the end of the projects highlighted that whilst institutions were interested in the provision of a national electronic detection facility, although hesitant about the cost of such a service, institutions also wanted a facility that would support their endeavours to combat the problems, both real and potential, posed by the wealth of information sources now freely available (Condron, 2001). In April 2002 therefore, interested parties were invited to bid for the JISC contract to provide a national Plagiarism Advisory Service and join a small coterie of JISC funded information services that includes:

- TechDis, providing advice on disability and accessibility issues,

- J-LIS, providing information on legal issues in higher and further education

and more recently, 
- JISCInfonet, providing advice on information systems implementation and

- BMAS, providing advice on Bandwidth Management.

The successful bid was the result of a collaborative proposal by Northumbria University's Learning Resources department and the Information Management Research Institute, then based in the School of Information Studies at Northumbria but now part of the broader School of Informatics. Both Learning Resources and the Information Management Research Institute have strong backgrounds in user-centred research and a well developed customer service orientation, and these elements were important features of the ultimately successful bid.

\section{Service structure}

From the outset it was acknowledged that whilst Learning Resources and IMRI contained a wealth of experience in relation to information management and information provision, providing the breadth of advice and guidance required of the new service meant also looking beyond the immediate confines of these departments, not only into other departments of Northumbria University, but also into the wider education community. The service is, therefore, structured in such a way that we are able to call upon the services of two specific groups of people:

1. An Expert Group, comprised of individuals in Northumbria University with expertise in specific areas relevant to the issue of plagiarism, i.e. law, quality assessment, data protection etc., and

2. A Round Table, comprised of acknowledged UK experts in a number of relevant areas, e.g. copyright, staff development, helpdesk provision and student support as well as representatives of the FE community and the publishing industry.

In addition to these two groups the service also has a management board that includes representation from within Northumbria University, local FE institutions and an international representative from a European education institution.

This diversity of background and experience is intended to ensure that the service provision is deliberately wide-ranging in its' focus, and appeal.

\section{Electronic Detection Service}

In tandem with the tender process for the Plagiarism Advisory Service, the JISC also invited bids from interested parties to provide a national electronic Plagiarism Detection Service. The contract for this service was awarded to iParadigms, a software development company based in California. Their software programme "turnitin" was already 
extensively employed in US education institutions. The software offers UK institutions, for the first time, the capacity to identify both plagiarism from internet sources and collusion amongst, and between, student groups with one programme, thereby addressing one of the main concerns expressed by academics in the survey conducted by Bull et al. (n.d.). In addition, the provision of a national facility retaining student work also offers, in the long term, the capacity to identify plagiarism from previous students' work. The software works by producing a 'digital fingerprint' of a submitted paper, which is then checked against the service database of previously submitted papers and internet resources. The software then produces an'originality report' (See Figure 1) that highlights the matches found and provides details of the original sources. It is important, however, to note that the software does not distinguish between properly referenced text and unacknowledged quotes, thus the judgement as to whether plagiarism has occurred remains with the lecturer viewing the report.

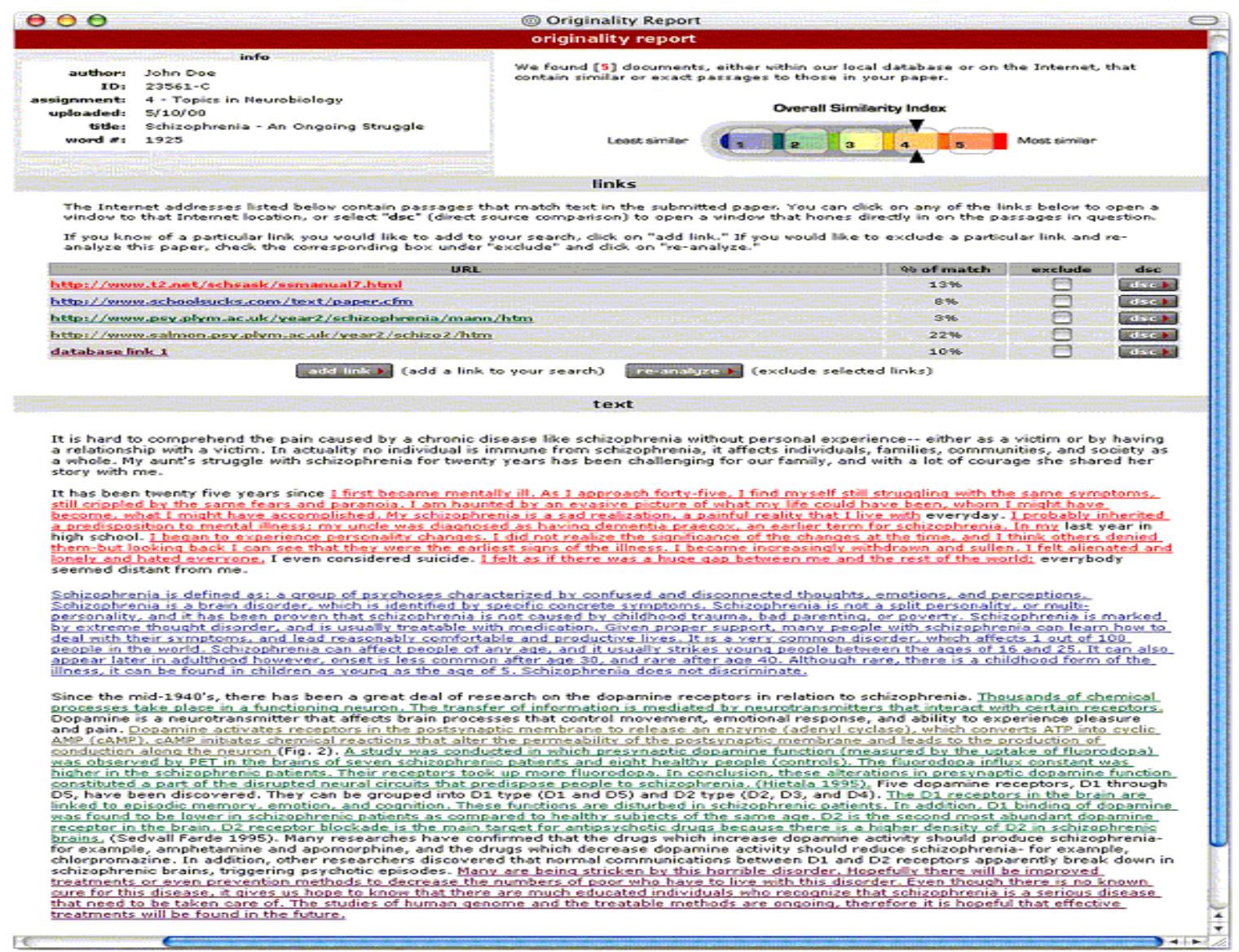

Figure 1: Originality report

The 'originality report' is currently produced within four hours of paper submission, although the next upgrade of the system in late summer / early autumn will reduce the turnaround time to fifteen seconds. This is in contrast to the twentyfour hour turnaround experienced by the institutions involved in the pilot projects, which was considered one 
of the major drawbacks of the software (Bull et al. n.d.) In order to address the slow response times to queries, also experienced by the pilot sites, the helpdesk support for the detection service is housed within the Advisory Service at Northumbria University. Electronic detection tools should be viewed as additional elements of a strategy designed to prevent plagiarism rather than a complete solution to the problem. Indeed, the Advisory Service recommend that registration for the Detection Service is enacted through Learning Resources or Learning and Teaching Support units, where applicable, as these individuals are able to address the wider issues, such as student concerns over inadvertent plagiarism highlighted in the pilot reports, when promoting the service within their own institution.

Electronic detection software programmes can, for example, speed up the process of identifying possible sources of plagiarised work but are not infallible, and should, therefore, be seen as complementary to 'soft' solutions such as knowing students' capabilities, identifying changes in their writing styles and using every opportunity to discuss referencing and citation practice. Electronic detection will deter many students from colluding or plagiarising but will not deter, and may even encourage, students who see this type of software as a challenge rather than a threat. Indeed these students may place more effort in trying to 'beat the system' than they would otherwise expend in completing the assessment. Electronic detection must, therefore, be used with these caveats in mind.

\section{Service users}

The Plagiarism Advisory Service website, http://www.jiscpas.ac.uk, (See Figure 2) which was launched in mid-September 2002, is the main delivery mechanism for the service, although the service also hosts a discussion list, and raises awareness through attendance at conferences and seminars, and organising workshops in conjunction with the JISC Regional Support Centres. The first resources made available on the website were the reports produced from the JISC pilot studies. Although the service has been successful in identifying and obtaining a host of relevant material for our users, our monitoring process indicates that the Good Practice report produced by Carroll and Appleton (2001) remains the most frequently downloaded publication by visitors to the website. This is particularly encouraging as, although electronic detection is embedded within the Advisory Service provision, the focus of the Advisory Service guidance is very firmly upon identification and dissemination of good practice. Good practice in this context relates not only to referencing and citation practice, but also to teaching and assessment design, establishing and maintaining institutional policies and procedures, and setting penalties and tariffs for academic misconduct cases. The service, therefore, seeks to identify and collate material relating to all of these areas for inclusion on the website.

Our monitoring process also indicates that whilst the Advisory Service was established to serve a UK audience in fact a significant number of visitors to our website are based outside of the UK. Indeed, as the list of international visitors continues to grow it is apparent that education providers around the world share the concerns that led to the initial establishment of the Plagiarism Advisory Service. It is also apparent that the user- 
centred approach advocated by the Advisory Service is also appropriate in an international as well as domestic context.

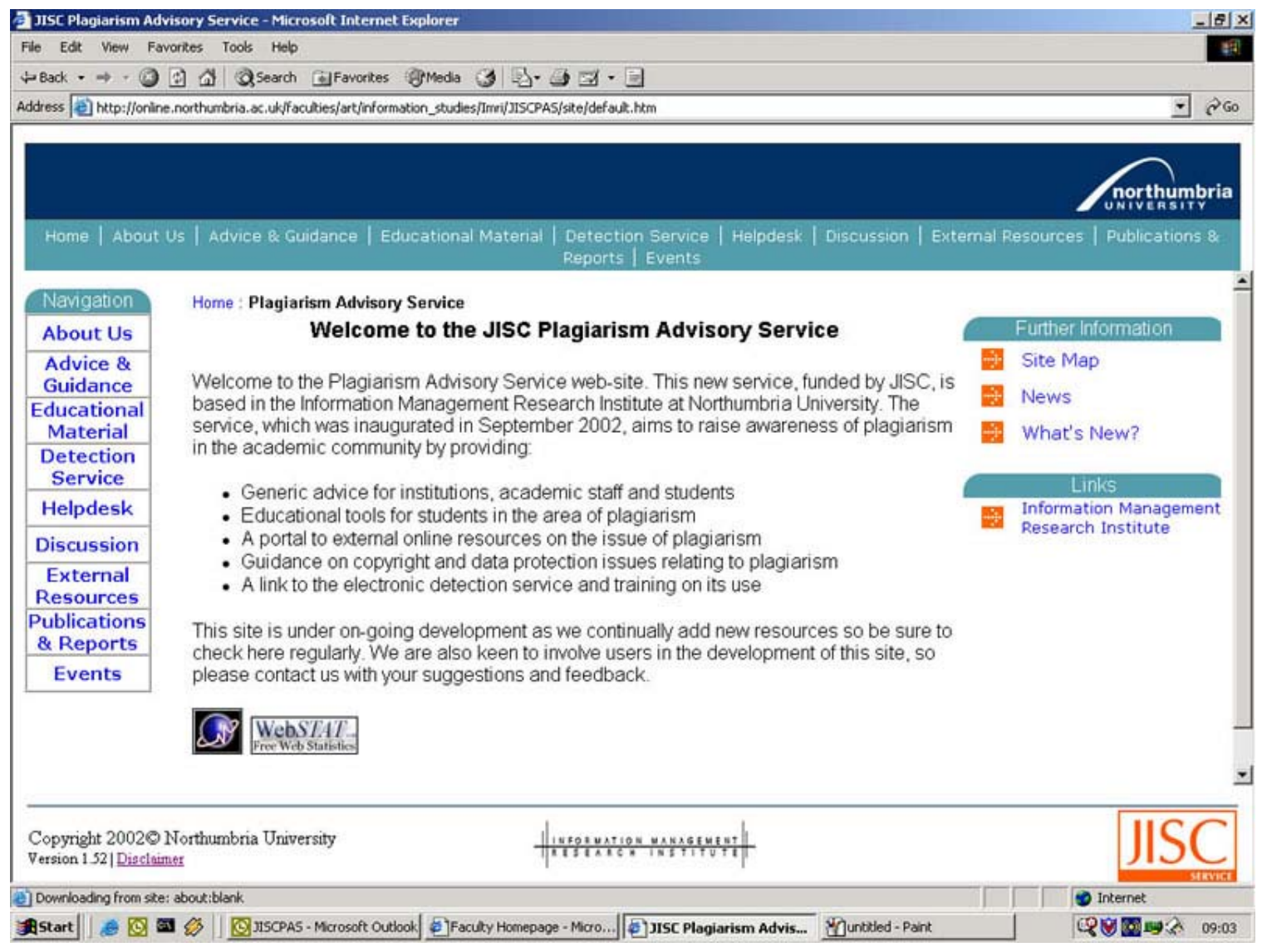

Figure 2: JISCPAS Home page

\section{Future plans}

The primary aim for the first few months of the Plagiarism Advisory Service was to source relevant material for the service website. Whilst this activity will be on-going throughout the life of the service, a range of other activities are planned for the second year of the service. A series of regional workshops aimed at raising awareness of the issues surrounding plagiarism are currently being held at venues throughout the UK. Workshop venues and booking details are available on the Advisory Service website. The workshops are designed, not only to introduce participants to the role of technology in detecting plagiarism, but also to stress the importance of assessment design and the consistent application of policies in the prevention of plagiarism.

Future plans for the service include a collaborative venture with Netskills to develop training workshops for users of the detection service and the development of two tools intended to help students, academics and support staff prevent 'inadvertent plagiarism.' The first of these tools will be an interactive learning tool aimed at providing students 
with a self-test package. The package will be designed to assess the students' knowledge of copyright, referencing and citation practice, and will provide links to appropriate resources where gaps in their knowledge are identified. The learning tool will have a clear emphasis upon referencing electronic resources, as this is felt to be a particular concern for students.

The service is also in the early stages of developing an assessment audit tool, which will be initially aimed at academics, although potentially a series of audit tools intended for support staff, senior managers, etc may also be developed. This will, however, depend to some extent upon the expressed demand for such a tool and the ability of our Round Table members to find the time to develop the series. The audit tool is intended to assess where potential problems in existing practice may exist, and to highlight possible activities that will help address these problems. We are aware of the importance of involving learning resources staff in any institutional activities relating to plagiarism as their role as information specialists will be of tremendous benefit in supporting plagiarism prevention activity.

Both of the tools are in the very early stages of development and announcements about the progress of these initiatives will be posted on the Advisory Service discussion list at PLAGIARISM@JISCMAIL.AC.UK. Details of new additions to the website and workshop dates and venues are also posted to the discussion list to ensure that our users are kept up-to-date with all of the service activities.

The Advisory Service is keen to ensure that it responds to the needs of the academic community. We therefore encourage visitors to the website to contact us if they are aware of particularly appropriate material that is not yet available on the website. The response from the community in the first few months of our activity has been extremely positive, and our challenge for the future is to ensure that the advice and guidance we provide continues to support all members of the academic community in their endeavours to maintain the integrity of the awards bestowed. 


\section{References}

Bull, Joanna et al., (n.d.) Technical review of plagiarism detection software report. CAA University of Luton

http://online.northumbria.ac.uk/faculties/art/information_studies/Imri/Jiscpas/docs/jisc/lut on.pdf [accessed 19/06/03]

Carroll, Jude and Appleton, Jon (2001) Plagiarism : A good practice guide Oxford Brookes University

http://online.northumbria.ac.uk/faculties/art/information studies/Imri/Jiscpas/docs/brook es/brookes.pdf [accessed 19/06/03]

Chester, Gill (2001) Pilot of free-text electronic plagiarism detection software JISC

http://online.northumbria.ac.uk/faculties/art/information_studies/Imri/Jiscpas/docs/jisc/Pi lot_final_report2.pdf [accessed 19/06/03]

Condron, Frances (2001) Plagiarism and the internet : report on the electronic plagiarism detection workshop organised by Gill Chester of the JISC held in London on the $16^{\text {th }}$ July 2001. Learning Technologies Group Oxford University Computing Services http://www.oucs.ox.ac.uk/ltg/reports/plag.shtml [accessed 19/06/03]

Culwin, Fintan. McLeod, Anna \& Lancaster, Thomas (2001) Source code plagiarism in UK HE computing schools : issues, attitudes and tools. South Bank University http://online.northumbria.ac.uk/faculties/art/information_studies/Imri/Jiscpas/docs/jisc/so uthbank.pdf [accessed 19/06/03]

Word Count : 2367 